\title{
The Relative Importance of Aspects of Intellectual Capital for Software Companies
}

\author{
Sebastian Barney ${ }^{1,2}$, Aybüke Aurum ${ }^{2}$, Claes Wohlin ${ }^{1,2}$ \\ ${ }^{1}$ Blekinge Institute of Technology, Sweden \\ sebastian.barney@bth.se, claes.wohlin@bth.se \\ ${ }^{2}$ School of Information Systems, Technology and Management \\ University of New South Wales, Australia \\ aybuke@unsw.edu.au
}

\begin{abstract}
Intellectual capital (IC) is both the key input and tool used in the development of software today. It covers the value provided to an organisation by the employees, the processes and products that support the organisation, and the knowledge held in the relationships between the organisation and external parties - covering human capital, structural capital, and relationship capital respectively. This paper presents a method that seeks to understand the level of alignment between the different success-critical stakeholders in the importance of different aspects of intellectual capital. The method is applied in a case study and provides a number of interesting insights, with the authors concluding that the groups do not necessarily need to be aligned as each groups has a different informational role within the organisation to fulfil.
\end{abstract}

\section{Introduction}

Much of the value of a company is in its intangibles, which include assets like brands, customer relationships and the knowledge and experience of their employees. These assets represent the intellectual capital (IC) of an organisation. IC is an increasingly important resource for companies today due to the rise of the knowledge-based economy [18]. It is both the key input and tool in the development of software, but both IC and software pose problems for managers as they are both intangible in nature and difficult to express in monetary terms. The challenge is for software companies, as part of their business strategy, to assess their competency needs and ensure that they get the best return from their IC while providing the value to their customers.

Managing IC, which requires identifying IC indicators in an organisation, developing and measuring it and aligning
IC to the organisation strategy and leveraging it for competitive advantage, is now recognised as an important strategic approach for increasing organisations wealth $[14,21,7]$.

Previous literature identifies three categories that form the concept of IC, namely human capital, structural capital and relational capital; each of these is composed of candidate indicators [21]. The relevant list of indicators and several classification dimensions haven been used as a basis for measuring IC of an organisation. The selection of IC measurement indicator is a multi-decision problem which requires involvement of various stakeholders. In order to assist managers decision making in selecting IC indicators measurement, this article suggests an approach for comparing the priorities placed on aspects of IC by different sections of an organisation.

This paper proposes an empirical method for comparing the priorities placed on aspects of IC by different sections of software organisations. The method was applied to a case study in Ericsson involving a range of business and technical perspectives.

This paper is structured as follows: Section 2 presents the background and concludes with the research questions covered in this paper. Section 3 presents the method, which is then applied in a case study in Section 4. Finally the discussions are presented in Section 5 and conclusions in Section 6.

\section{Background}

\subsection{Models of Intellectual Capital}

In early 1990s, Tom Stewart defined IC in an article in Fortune [19] as the sum of everything a company owns that gives a competitive edge in the market place, including knowledge and experience of people [21]. 
The origin of the IC concept can be traced to the balanced scorecard, which was developed by Skandia a multinational insurance and financial services company based in Stockholm. Skandia proposed IC as a management tool for the first time, with an objective to better manage intangible assets when creating further sustainable value for the organisation [7]. Dow Chemical, with collaboration with Skandia defined the components of IC in terms of human capital, organisation capital and customer capital [14].

Although there have been attempts to develop a general IC model, organisations tend to customise the model for their own environment [11].

Brooking [6] defined fours aspects of IC: market assets, human centric assets, intellectual property assets and infrastructure assets. Lowendahl [15] identifies intangible assets in terms of competence and relational resources. Sullivan [20] develops a model based on human capital and defines human capital as the capabilities of stakeholders which is supported by structural capital e.g. computers and information systems.

Bontis [5] divided IC into human capital, relational capital and structural capital with several indicators that each described. Human capital is the capabilities of individuals who provide solutions to customers. These include knowledge, experiences, skills and abilities of employees, combined human ability to solve business problems. Structural capital refers to the structures and processes within the organisation that meets market requirements e.g. patents, trademarks, information systems. Relational capital refers to an organisation's relations with stakeholders including customers, suppliers and public. This model is one of the frequently used models by practitioners and academics.

\subsection{Measuring IC}

Previous research and business practices have led to various models and indicators of IC [21, 20, 10].

There are several techniques, systematic processes and models used to measure IC of organisations. These include balanced scorecard, relative value, competency models, subsystem performance, benchmarking, business worth, business process auditing, knowledge bank, brand equity valuation, calculated intangible value, micro-lending, colorised reporting [16].

Over the years, several methods of measuring IC have also been developed e.g. Skandia Navigator, Intellectual Capital Services' IC Index ${ }^{\mathrm{TM}}$ and Philip M'Phersons Inclusive Valuation Methodology $\left(\mathrm{IVM}^{\mathrm{TM}}\right)$ [12]. The starting point of every method is the identification of intellectual assets and grouping them into categories. For example, Skandia's Navigator model includes 112 indices of IC whereas Edvinsson and Malone measure IC by developing 140 indicators, using four perspectives, namely financial, customer, human, and renewals and development [12].

Han and Han [11] used analytic hierarchical process (AHP) to prioritise and select indicators of IC for the mobile telecommunications industry. This method appears useful in supporting management identify and create a better IC environment within their organisation, however, it cannot be used to describe the current situation and requires a topdown approach - limiting the possible involvement of some stakeholder groups.

While many researchers have examined attributes of IC, there appears to have been no systematic attempt in the intellectual, structural or human capital literature to list the attributes that constitute these areas of study until very recently $[17,8]$. Most researchers have only examined aspects of these areas, recognising any list of attributes as incomplete. Moon and Kym [17] noted without a clear and comprehensive framework for IC managers are likely to lack the detail required to effectively manage their organisations IC, so they created a model of IC by synthesising the attributes and model fragments from many studies. This model is used in this paper.

\subsection{Benefits and Limitations of Measuring IC}

Measuring IC has several benefits. For example it allows company to assess the risk present and identify areas to develop and improve, it provides a systematic approach when comparing several units within a company or companies, it provides very useful information on companies' future potential and helps providing a comprehensive company report.

Benefits can be direct, indirect or long term [9]. Direct benefits improve financial performance of the organisation. Indirect benefits are related to changes in elements of performance which may be beneficial for the company e.g. motivating staff members which allows managers to be more productive or increase in code reuse or reduction in testing time. Long term benefits include an improvement of the relationships within a company.

The longer-term challenge is leveraging human capital and transforming it into structural capital, while creating value for the company. Hence, it is important that managers understand the meaning of IC and appreciate the value of IC solutions as this will help them to better understand what really matters for the survival and sustainable of their organisation in knowledge intensive society.

Although measurement of IC has several benefits to a company, this is costly process because of the time needed to collect the data, analyse it and take actions on those measurements. In order to lower the cost, companies may need to automate the measurement and cut down on the number of people involve in the process as in many cases benefits 
achieved are difficult to quantify [9].

\subsection{A Value-Based Approach to Intellec- tual Capital}

Issues often arise in the development of software as it involves many conflicting groups, each with their own perspective of what is important. Value-based software engineering (VBSE) recognises the problems created by conflicting perspectives in the software development process [3] and seeks to resolve these conflicts using Theory$\mathrm{W}$, which requires [4]:

1. Success-critical stakeholder groups to be identified;

2. The requirements of these groups to be elicited;

3. Negotiation between the groups to create a win-win situation; and

4. A control process to support success-critical stakeholder win-win realisation and adaption to a changing environment.

The key advantage of Theory- $\mathrm{W}$ is that it explicitly brings all of the parties on whom success lies together to understand each other's needs, compromise and agree. But in order to be successful Theory-W must be managed to ensure the plans are achieved and any deviations from the plans are corrected [4]. Management requires an understanding of why the goals are being pursued, what is the required result, who is responsible for the result, how the result will be achieved and at what cost the result can be achieved. The answer to these questions will be specific to the context in which they are answered.

\subsection{Research Objectives}

The selection of IC indicators require involvement of several stakeholders. The objective of the research presented in this paper is to create and validate a method capable of determining the level of alignment between the internal success-critical stakeholder groups in the process of prioritising IC indicators for a software company. The method should be able to identify the degree to which the groups are aligned in how they perceive operations today with respect to quality.

This method is evaluated in an industrial case, answering the research questions presented in this section.

$R Q 1$ : Is the method proposed in this paper capable of identifying the degree to which the internal success-critical stakeholder groups are aligned in how they perceive the priorities on aspects of IC today?

However, alignment itself only ensures that the successcritical stakeholder groups have a common understanding of what is happening today, it does not mean the groups agree this is what should be happening today. As each group represents a different, and potentially conflicting, perspective on the aspects of IC it is important to discover what each of these groups perceive should be happening in a hypothesised ideal situation. This is addressed by the second research question:

$R Q 2$ : Is the method proposed in this paper capable of identifying what the different internal success-critical stakeholder groups perceive as the ideal set of priorities on aspects of IC in the situation today? And to what degree are the groups aligned?

\section{Method}

The method presented in this paper is built on TheoryW. By exploiting the early phases of Theory-W it is possible to determine the level of alignment between the internal success-critical stakeholder groups. This involves identifying the internal success-critical stakeholder groups and eliciting their value propositions with respect to aspects of IC.

An initial workshop should be held to choose a model appropriate to the needs of the organisation and ensure the terms and definitions can be understood by the intended participants. This workshop should include representatives of the success-critical stakeholder groups identified.

The results should support the continued application of Theory-W, to negotiate between the success-critical stakeholders to achieve a better situation and realise this goal through clearer management.

\subsection{Questionnaire}

This method proposes the hierarchical cumulative voting (HCV) technique [2] to elicit (a) how important each aspect of IC is today, and then repeated the exercise to show (b) how important they perceived each aspect of IC should be today in a perceived ideal situation.

$\mathrm{HCV}$ is made up of a number of cumulative voting $(\mathrm{CV})$ exercises. CV asks participants to spend 1000 points across different sets of previously identified attributes to represent their relative influence. For example, if a participant thought employee satisfaction does not at all matter today and employee capability was twice as important as employee sustainability they might award these qualities zero, 200 and 100 respectively. HCV is able to consolidate the result of multiple CV exercises into a single list of attributes with relative weights.

The method presented in this section proposes using the model of IC proposed by Moon and Kym [17], covering 17 aspects of IC. The method employs one CV exercise for each of the three broad categories of IC - human capital, structural capital and relationship capital - and one list for 
each of these categories, each containing the relevant aspects.

\subsection{Analysis}

HCV and CV allows participants' responses to be grouped logically for analysis - for this method into the success-critical stakeholder groups. The results of each participant in the group can be averaged, ultimately producing a list that shows each aspect of intellectual capital and the averaged notion of its importance.

In order to conduct the analysis each participant's response needs to be changed from $\mathrm{HCV}$ to $\mathrm{CV}$, converting the four cumulating voting lists into a single list that covers all aspects of IC.

Remembering that three of the lists cover the attributes that make up the categories human capital, structural capital and relationship capital, while the remaining list gets participants to compare these categories. This allows the number of points to be awarded to each quality to be multiplied with the category from which it came [2] - to ensure that qualities with many categories are not underrepresented and that categories with few qualities are not overrepresented. It is also necessary to multiply each of these results by the number of qualities from the same category as the resultant value. Finally the set of numbers for each quality can be scaled so that the sum is 1000 .

For example, if 200 points are awarded to human capital and 600 points are awarded to employee capacity, then category $*$ quality $*$ numberofqualities $=200 *$ $600 * 2=240,000$. The scaling of this result then depends on the other values, but if the other values were to sum to $4,800,000$ then the number would be scaled to result/totalsum $* 1000=240,000 / 4,800,000 * 1000=$ 50 .

The individual responses can now be grouped and averaged, allowing ranks to be determined and the Spearman rank correlation can then be calculated.

\subsection{Review}

For a deeper understanding of the results a second workshop is held to review the results, with representatives of the success-critical stakeholder groups.

\section{Case Study}

The case study was conducted during Spring 2008 for one product at Ericsson. Ericsson is a world leading company in telecommunication, providing a wide range of products and solutions. Products are developed and sold as generic solutions offered to an open market, although customised versions of the products are also developed.

\subsection{Success-Critical Stakeholder Groups}

High-level R\&D management supported the authors to identify internal success-critical stakeholder groups for this case study. Participants in the case study represent:

- Development (Dev) are responsible for the implementation of requirements.

- Testing (Test) are responsible for the verification and validation of requirements.

- Line Managers (Line) are responsible for teams of employees. These responsibilities include hiring, training and support.

- Human Resource Managers (HR) provide support to line managers in the hiring, training and other aspects of staff management.

- Project Managers (PM) are responsible for planning and executing projects aligned with the priorities of the strategic product management.

- Tactical Product Management (TPM) support the strategic product management with expert knowledge of the systems and their architecture. They are also responsible for providing analysis of pre-project requirements in the form of feasibility, impact and technical dependencies.

- Strategic Product Management (SPM) have the strategic product responsibility and decide the overall product development direction.

A description of this case study was sent out to the managers of the identified success-critical stakeholder groups requesting volunteers from their teams to take part in the case study.

In total 44 potential participants were identified to take part in this case study, with 32 usable results being obtained, with breakdown of the participants can be seen in Table 1. The candidates who did not participate either had to cancel due to late arising conflicts in their calendar or were unable to make time due to other commitments.

The questionnaire was conducted as a one-on-one structured interview, which each participant taking between 25 and 60 minutes. The interviews were conducted over a twomonth period.

\subsection{Aspects of Intellectual Capital}

The authors initially selected the model of IC proposed by Moon and Kym [17] to form the foundation of this case study. This is a recently developed model that aims to provide complete coverage of the concepts of IC. 
Table 1. Study response rate

\begin{tabular}{lrr}
\hline Group & Candidates & Responses \\
\hline Development (Dev) & 8 & 6 \\
Testing (Test) & 9 & 8 \\
Line Mgmt (Line) & 2 & 2 \\
Human Resources (HR) & 1 & 0 \\
Project Mgmt (PM) & 4 & 4 \\
Tactical Product Mgmt (TPM) & 8 & 8 \\
Strategic Product Mgmt (SPM) & 8 & 4 \\
Total & 44 & 32 \\
\hline
\end{tabular}

To maximise the relevance of the results to Ericsson an initial two-hour workshop was held to ensure the terms covered the desired aspects of IC and definitions would be clear to the intended audience. A number of changes to the model were agreed to by the five people in attendance, who represented a range of roles. These changes are detailed in the remainder of this section.

The most significant change involved expanding customers to differentiate between the purchasers of solutions, users of solutions, and users of telephone services. Examples of organisations that would be covered by some of the aspects of relationship capital were also included.

The workshop participants also agreed that two aspects of IC management should be covered - institutionalisation and adaptability. These were included as an extra category, which was called Management. The questionnaire was updated to include the extra category in the main CV exercise, and an addition $\mathrm{CV}$ exercise was added covering these two aspects.

The terms used in the case study presented in this paper are presented in Figure 1. The definitions of the terms used and the questionnaire are available online [1], with the examples tailored to the organisation removed.

\begin{tabular}{|c|c|c|c|c|}
\hline \multicolumn{4}{|c|}{ Capital } & \\
\hline Human & Strucural & Relatic & onal & \\
\hline 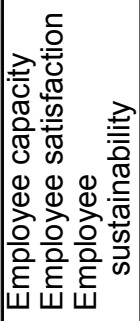 & 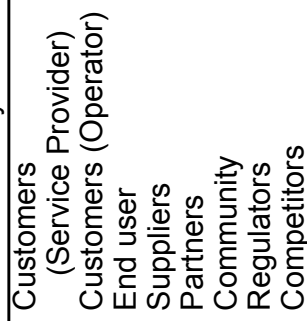 & 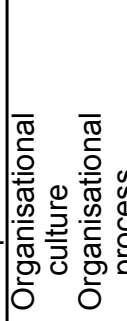 & 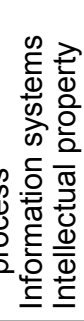 & 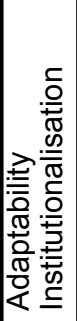 \\
\hline
\end{tabular}

Figure 1. Model of IC used in Study

\subsection{Alignment in Aspects of Intellectual Capital}

Analysing the results of the questionnaire it is possible to produce a list ranking the aspects of intellectual capital from most to least influential for each group. Comparing the groups using the Spearman rank correlation shows the degree to which the groups are aligned in how they have prioritised these elements.

The results in Table 2 show the degree to which the success-critical stakeholder groups are aligned in their perception of the priority placed on the different aspects of intellectual capital today.

Table 2. Correlation Matrix: Alignment Today

\begin{tabular}{lcccccc}
\hline & Dev & Test & Line & PM & TPM & SPM \\
\hline Dev & 1.00 & 0.43 & 0.49 & 0.48 & 0.74 & 0.31 \\
Test & 0.43 & 1.00 & 0.64 & 0.75 & 0.62 & 0.63 \\
Line & 0.49 & 0.64 & 1.00 & 0.49 & 0.43 & 0.46 \\
PM & 0.48 & 0.75 & 0.49 & 1.00 & 0.63 & 0.63 \\
TPM & 0.74 & 0.62 & 0.43 & 0.63 & 1.00 & 0.34 \\
SPM & 0.31 & 0.63 & 0.46 & 0.63 & 0.34 & 1.00 \\
\hline
\end{tabular}

Most groups stand out as being more aligned with one or two groups. For example, Development is clearly more aligned with TPM than the other groups. The exception to this rule is in Testing, which stands out as being highly aligned with most groups.

Participants were also asked about what they perceived should be happening today, in a perceived ideal situation. The alignment of the success-critical stakeholder groups for these results are presented in Table 3. These results show that the level of agreement between the groups changes as each prioritises the aspects of intellectual capital in the way they perceive optimal.

Table 3. Correlation Matrix: Alignment in Ideal Situation

\begin{tabular}{lrrrrrr}
\hline & Dev & Test & Line & PM & TPM & SPM \\
\hline Dev & 1.00 & 0.63 & 0.57 & 0.74 & 0.60 & -0.06 \\
Test & 0.63 & 1.00 & 0.78 & 0.68 & 0.51 & 0.31 \\
Line & 0.57 & 0.78 & 1.00 & 0.66 & 0.59 & 0.37 \\
PM & 0.74 & 0.68 & 0.66 & 1.00 & 0.64 & 0.19 \\
TPM & 0.60 & 0.51 & 0.59 & 0.64 & 1.00 & 0.54 \\
SPM & -0.06 & 0.31 & 0.37 & 0.19 & 0.54 & 1.00 \\
\hline
\end{tabular}

It is also possible to see how much change each group perceives necessary by looking at the correlation between 
how they perceive the situation today, and what they perceive should be happening today. These results are presented in Table 4, with one indicating no change, and minus one indicating a complete reversal of priorities.

\section{Table 4. Correlation Coefficients: Today- Ideal}

\begin{tabular}{lr}
\hline Groups & Correlation \\
\hline All groups & 0.39 \\
Development & 0.38 \\
Testing & 0.55 \\
Line Management & 0.69 \\
Project Management & 0.36 \\
Tactical Product Management & 0.00 \\
Strategic Product Management & 0.45 \\
\hline
\end{tabular}

The results show that some groups are more satisfied with what is happening today than others. For example, line management perceive the least need for change with a correlation coefficient of 0.69 , while TPM perceive the greatest need for change with a correlation coefficient of 0.00 .

\subsection{Priorities in Intellectual Capital}

While confidentiality prevents the publication of the prioritised list of the aspects studied, this section presents a description of the key results.

In an examination of the combined results for all participants today, none of the four categories of IC - human capital, structural capital, relationship capital or aspects of IC management - stood out as being more or less important than the others. All of the groups, however, placed human capital in first or second place when describing the ideal situation, with the remaining categories again evenly mixed.

The most important aspects both today and in the ideal situation related to the customer with the operator and service provider in first and second place. While, the end user was perceived to be relatively less important today, there was a common perception this should change in an ideal situation.

Other results are more clearly associated with particular job roles. Line managers perceive human capital as the most important of the four categories today, with other groups all place this category third or fourth. There was greater consensus in the perceived ideal situation with a perceived need for a greater emphasis on employee sustainability and employee satisfaction.

Similarly SPMs were the only group that identified regulators as an important aspect of relationship capital, with many participants from other groups indicating they were not aware of any lobbying activities. The SPMs work with the group responsible for lobbying.

It was also felt that some aspects of IC should be relatively less important comparing the situation today with the ideal situation. The participants wanted to see a decrease in the importance of organisational process, suppliers, intellectual property, organisational culture and information systems.

\section{Discussion}

\subsection{Alignment in Aspects of Intellectual Capital}

The method was able to elicit a range of information about IC and its management in the case study presented in this paper. A two-hour review workshop was held with five people from a range of roles.

The participants of the workshop reviewing the results were not concerned by the low levels of alignment between some of the groups in what they perceived as important today or ideally with regard to IC. Due to the nature of different job roles, some aspects of IC will be perceived as more or less important by some groups. The clearest example of this is with line management today recognising human capital as the most important category of IC, while the other groups saw it as one of the least important. Line managers are charged with the responsibility of managing human capital through hiring, remuneration, training, etc. Similarly most roles do not need to follow potential changes to the legal environment, providing this task is taken on by somebody acting in the company's interest.

The workshop participants identified groups that they felt should be aligned, and were satisfied with the alignment between these groups in the situation today. These were $S P M$ and $P M, S P M$ and Testing, $P M$ and Testing, and TPM and Development. The correlation coefficient for these groups were respectively $0.63,0.63,0.75$ and 0.74 . These combinations took into account the roles and responsibilities of each group.

While the agreement between these groups is lower in the perceived ideal situation, the respondents answers were not made in consultation with the other groups to ensure that all knowledge-based activities occurred sufficiently.

The method in this paper only follows the first steps of Theory-W, so does not enter the negotiation stage where the identified issues can be resolved. By adopting the Delphi technique proposed by $\mathrm{Hu}$ et al. [13] it would be possible to exploit the later stages of Theory-W and harmonise the success-critical stakeholder value considerations. 


\subsection{Priorities in Intellectual Capital}

While Ericsson's customers are telephone service providers, it is perceived a greater understanding of phone end users will be beneficial to the business. While the current business model is largely reliant on the telephone operators representing their clients' interests, participants felt that greater involvement of the end user would produce better results.

The results also indicate the developers would benefit from a greater understanding of the customer in all its forms - the operator, service provider and end users. While they were provided with the information required to implement features and requirements for the software, comments indicate that the developers feel they would make more effective decisions in their job role with greater information about the context of the requirements. It was noted in the second workshop this may be related to the fact that developers usually only have direct contact with customers when things go wrong and a quick resolution is required, but to work this way for all requirements would be too inefficient. But the workshop participants did recognise that it was a tricky balance between overwhelming developers with information and just providing enough to develop the features requested.

Regarding the perceived need for a greater focus on $h u$ man capital, it should be noted that a number of factors were going on at the time of the questionnaire that could influence the results. The organisation had recently announced a restructuring of the departments developing the product studied, while a number of high tech businesses in the region were downsizing - creating a much tighter job market in the region. This study was also completed at the beginning of the global financial crisis.

The CV method means the increase in importance of an attribute must come at the cost of other attributes, as the method measures the relative importance between the set of attributes. The remainder of this section deals with the aspects of IC that were ultimately perceived as relatively less important in the ideal situation compared with the situation today.

Participants prioritised organisational process much lower in the ideal situation than the situation today. Comments from all groups indicated a growing number of controls to aid management in this regard, but the participants felt that controls remained in place even when they were no longer needed. This issue has been recognised by the management, with one of the key goals of the organisational restructure being to reduce the need for controls and decision points.

A similar situation may have occurred with information systems, as recently services have been moved from the HR department to the intranet - giving employees direct con- trol, but greater responsibilities. However, comments from a number of groups indicate that while much useful information is held within the supporting information systems, it is often much harder to retrieve than users of these systems believed it should be. Thus this result could be reflecting the idea that going forward the information will be easier to access, so requires less importance.

\subsection{Validity Threats}

The results of this study cannot be considered representative of the software industry, or even the Ericsson organisation, with all participants coming from one product produced by one company and responding to the same context. However, the results show the method can be used to check alignment between groups, and was able to identify a number of interesting issues.

It should be noted that it is easier for the participants to agree with the set of criteria identified by the researchers than disagree in the workshops and questionnaire. This is partially taken care of by allowing the participants to assign a relative importance of zero to aspects of IC.

It is also difficult to know whether the respondents have understood the questions as intended and in a similar fashion to one another. This threat was partially addressed in the third stage of this study where the results were presented in the second workshop for confirmation and discussion with the researcher.

\section{Conclusion}

The case study presented in this paper was able to identify a number of valuable and interesting issues of IC in a software development company, while also being able to address the research questions. In answering $R Q 1-$ to determine the level of alignment between the success-critical stakeholders in how they perceive the priorities on aspects of IC today - the authors found that the groups do not have the same priorities as each provides different informational needs of the organisation. Answering $R Q 2$ - to identify what the different internal success-critical stakeholder groups perceive as the ideal set of priorities on aspects of IC in the situation today - the authors found some consensus between the groups studied in terms of changes that could be made to improve the situation today.

The results of the case study presented indicated improvements could be made in the case studied though initiatives such as:

- Greater involvement and understanding of the end users,

- Sharing more background information about the 
sources of requirements and reasons for including it in a particular release,

- Constantly working to keep organisational processes lean and efficient, and

- Ensuring the information systems are able to easily support the common informational needs of all parts of the organisation.

However, the importance of the success-critical stakeholder groups being aligned in what they perceive as important was found to be less important that initially anticipated. As each of these roles aims to complete different tasks, the requirements on IC are different, which is matched by the priorities these groups place on different aspects of IC. It is more important that the organisation has been set-up to ensure that together the roles can efficiently and effectively get, share and use the information and knowledge it requires. However, this may still require some roles being aligned.

The method proposed could be used in other cases to help identify issues, and check alignment where it is deemed necessary. While it is not possible to generalise the results specific to this case, the method was able to identify a number of current issues in relation to IC for the organisation studied.

Going forward it would be beneficial to understand how the different groups relationship with aspects of IC and sharing of IC is able to meet the information requirements of the organisation effectively. As shown in the case study, this is not about ensuring that groups have access to the IC required for their job, but have access to the IC that best benefits the organisation. This could be supported by continuing the Theory-W process, using the Delphi technique to support negotiations between the success-critical stakeholders.

\section{Acknowledgments}

Claes Wohlin is currently a Professorial Visiting Fellow at the School of Information Systems Technology and Management at the University of New South Wales, Australia.

The authors would like to thank Ericsson for their active involvement in and support of this research.

This work was partly funded by The Knowledge Foundation in Sweden under a research grant for the project Blekinge Engineering Software Qualities (BESQ).

\section{References}

[1] S. Barney and C. Wohlin. Intellectual capital questionnaire. http://www.bth.se/tek/aps/sba, 2008.
[2] P. Berander and P. Jönsson. Hierarchical cumulative voting (hcv) - prioritization of requirements in hierarchies. International Journal of Software Engineering and Knowledge Engineering, 16(6):819-849, December 2006.

[3] B. Boehm and A. Jain. An initial theory of value-based software engineering. Value-Based Software Engineering, pages 15-37, 2006.

[4] B. Boehm and R. Ross. Theory-w software project management principles and examples. IEEE Transactions on Software Engineering, 15(7):902-916, 1989.

[5] N. Bontis. Assessing knowledge assets: a review of the models used to measure intellectual capital. International Journal of Management Reviews, 3(1):41-60, 2001.

[6] A. Brooking. Intellectual Capital: Core Asset for the Third Millennium. Cengage Learning EMEA, 1998.

[7] M. Bucklew and L. Edvinsson. Intellectual capital at skandia. The Foundation for Performance Measurement, 1999.

[8] E. Carson, R. Ranzijn, A. Winefield, and H. Marsden. Intellectual capital: Mapping employee and work group attributes. Journal of Intellectual Capital, 5(3):443-463, 2004.

[9] Cranfield. A report on the costs and the benefits of measuring intellectual capital assets. Technical report, Cranfield University School of Management, 2004.

[10] L. Edvinsson. Developing intellectual capital at skandia. Long Range Planning, 30(3):320-321, 366-373, 1997.

[11] D. Han and I. Han. Prioritization and selection of intellectual capital measurement indicators using analytic hierarchy process for the mobile telecommunications industry. Expert Systems with Applications, 26(4):519-527, 2004.

[12] T. J. Housel and A. H. Bell. Measuring and managing knowledge. McGraw-Hill/Irwin, Boston, Mass., 2001.

[13] G. Hu, A. Aurum, and C. Wohlin. Adding value to software requirements: An empirical study in the chinese software industry. In S. Spencer and A. Jenkins, editors, Proceedings of the 17th Australasian Conference on Information Systems. Australasian Association for Information Systems, December 2006

[14] A. Jashapara. Knowledge Management: An integrated Approach. Financial Times Prentice Hall, Harlow, 2004.

[15] B. Lowendahl. Strategic Management of Professional Services Firms. Handelshöjskolens Forlag, Copenhagen, 1997.

[16] Montague. Measuring intellectual capital. Technical report, Montague Institute, 2008.

[17] Y. J. Moon and H. G. Kym. A model for the value of intellectual capital. Canadian Journal of Administrative Sciences, 23(3):253-269, September 2006.

[18] G. Roos and J. Roos. Measuring your company's intellectual performance. Long Range Planning, 30(3):325, 413-426, 1997.

[19] T. A. Stewart and S. L. Kirsch. Brainpower - how intellectual capital is becoming america's most valuable asset. Fortune, June 1991

[20] P. H. Sullivan. Profiting from intellectual capital: Extracting value from innovation. Wiley, New York, 1998.

[21] K.-E. Sveiby. Intellectual capital and knowledge management. Technical report, Sveiby Knowledge Management, 1998. 